\title{
The Formation of Sulfide Scales on Carbon Steel in Saturated $\mathrm{H}_{2} \mathrm{~S}$
}

\author{
Noora Al-Qahtani ${ }^{1,2}$, Jiahui Qi ${ }^{1}$, Aboubakr M. Abdullah ${ }^{2}$, Nick Laycock ${ }^{3}$, and Mary Ryan ${ }^{1}$
}

${ }^{1}$ Department of Materials, Imperial College London, London SW1 7AZ, UK.

${ }^{2}$ Center for Advanced Materials, Qatar University, Doha P. O. Box 2713, Qatar.

${ }^{3}$ Qatar Shell Research and Technology Centre, Doha- Qatar.

Introduction

The damage caused by the building up of scale inside wellbores and pipelines costs millions of pounds each year. Better understanding of the mechanism of scale formation and the kinetics of the process is essential, for asset management in general and for the development of new protection approaches. Surface scale formation is one of the important factors related to the corrosion rate in sour systems. The internal corrosion of carbon steel in the presence of hydrogen sulfide represents a significant problem for both oil refineries and gas treatment facilities/pipelines. Many studies have revealed that the system is complex: more than one iron sulfide compound may form and its morphology is sensititvely dependent on environmental conditions. However, the kinetics of scale formation, such as the nucleation and growth processes of the scale; and how corrosion inhibitors interact with nanoscale morphology of the scales are not at all well-understood

Experimental setup

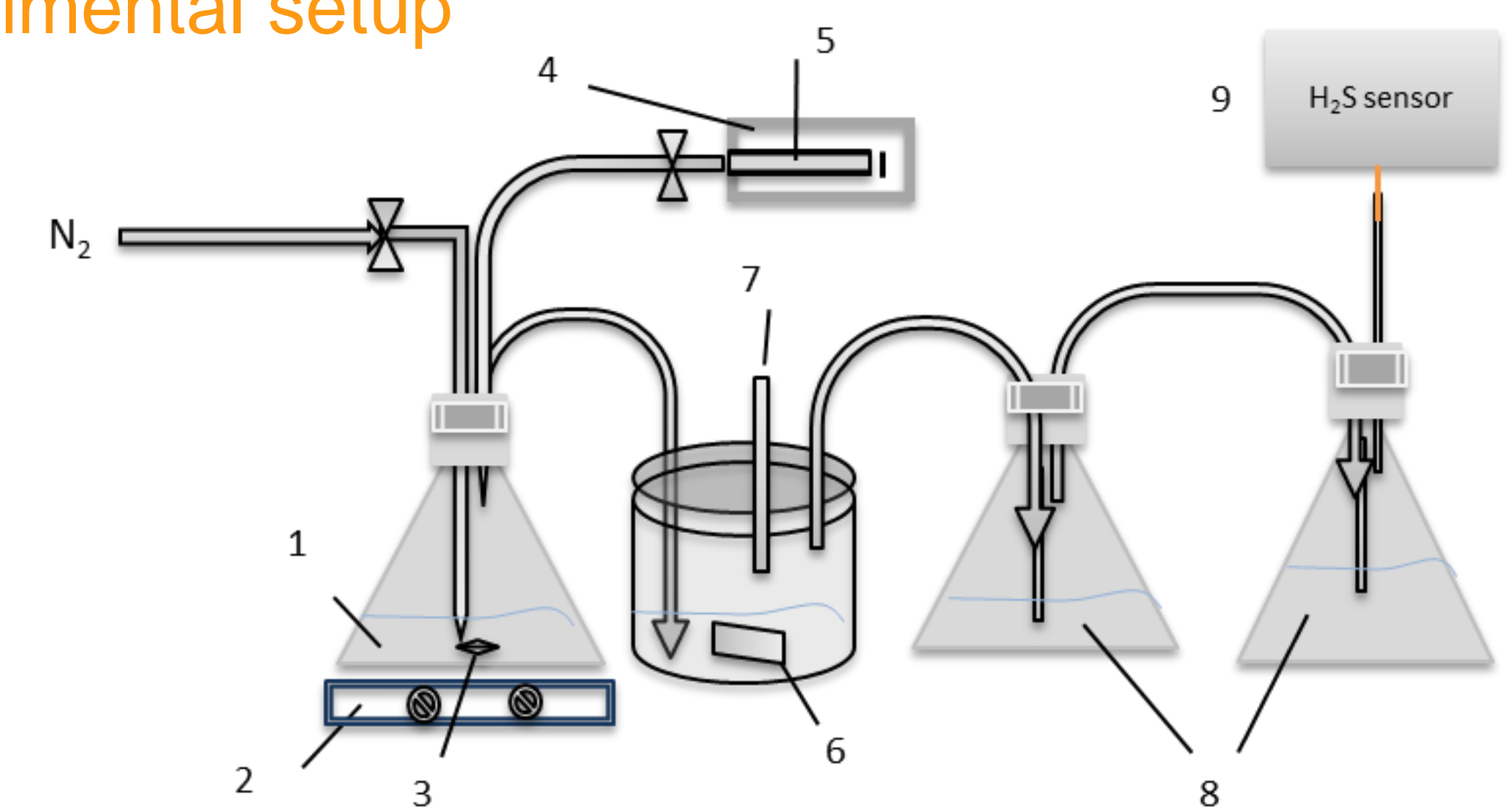

Ambient pressure

set-up for in-situ

$\mathrm{H}_{2} \mathrm{~S}$ generation

1 Sodium sulfide solution; 2 Stirring hot plate; 3 Stirrer bar; 4 syringe pump; 5 Syringe filded

with Diluted $\mathrm{HNO}_{3}$ solution; 6 Iron sample; $7 \mathrm{pH}$ meter; $8 \mathrm{H}_{2} \mathrm{~S}$ scrubbers; $9 \mathrm{H}_{2} \mathrm{~S}$ sensor.

The system allows for saturated hydrogen sulfide solution, temperature control, and export of the sample to high pressure environment for repeat assessment.

\section{Results and Discussion}

Scale formation was investigated as a function of temperature and time. Visual inspection reveals increasing apparent density with temperature and thickness of the scale with time.

\begin{tabular}{|c|c|c|c|c|c|}
\hline Temp / Time & $10 \mathrm{~min}$ & $30 \mathrm{~min}$ & $1 \mathrm{hr}$. & $1.5 \mathrm{hr}$. & $2 \mathrm{hrs}$ \\
\hline RT & & & & & \\
\hline $50^{\circ} \mathrm{C}$ & & & & & \\
\hline $80^{\circ} \mathrm{C}$ & & & & & \\
\hline
\end{tabular}

$\mathrm{pH}$ measurement of the solution is essential because it affetcs the solubility metals such as iron, and in turn provides information about the saturation conditions of the system. At RT, pH drops in the first 20-30 min then rises and stabilizes at $\mathrm{pH} 4-5^{\circ}$, at $50{ }^{\circ} \mathrm{C}$, after an initial drop there is an increase $\mathrm{pH}$ 6-7, before stabilising at a similar value. This temporal variation strongly affects the rate $\mathrm{Fe}$ dissolution.

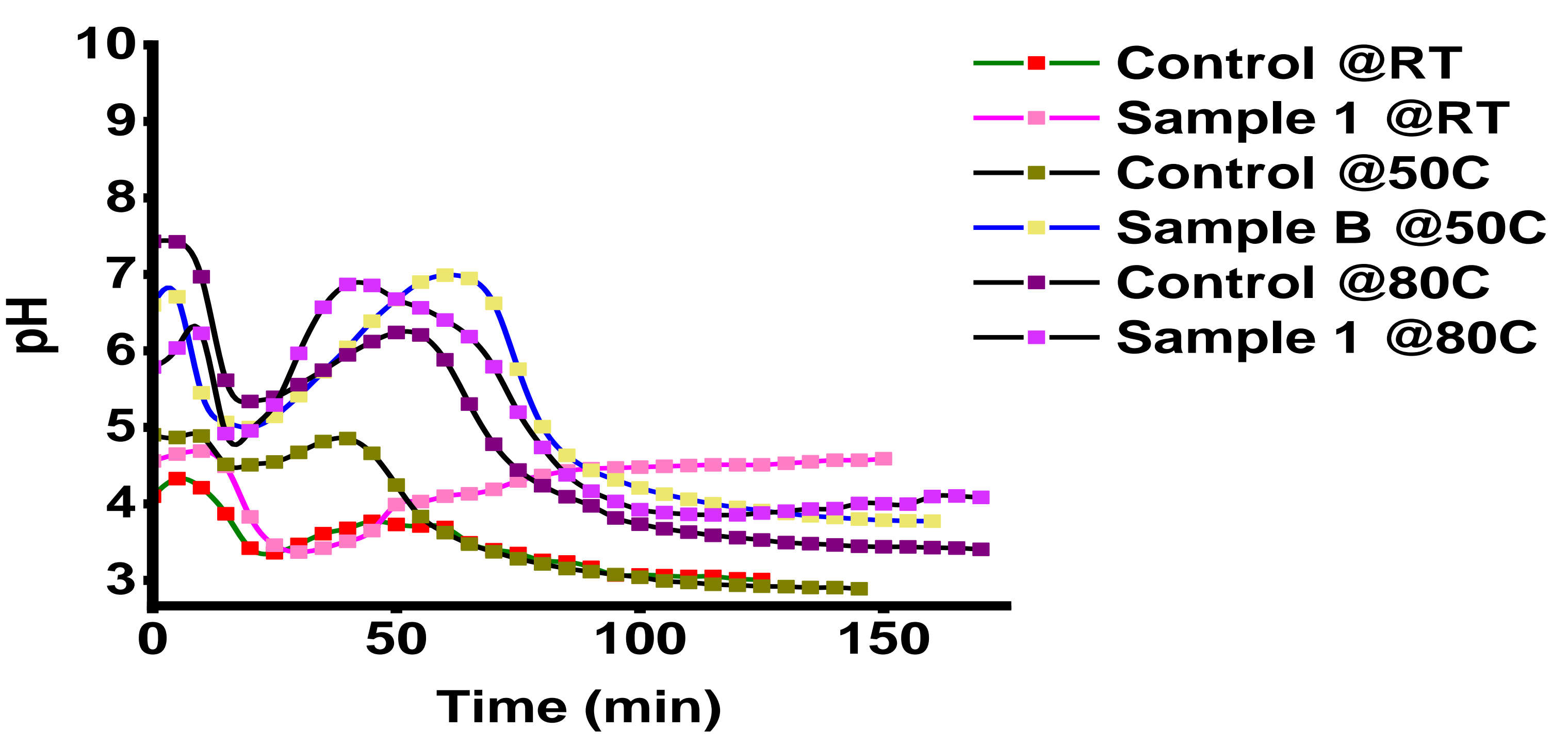

Figure 2: Solution $\mathrm{pH}$ change with time at different temperature: $\mathrm{RT}, 50^{\circ} \mathrm{C}$ and $80^{\circ} \mathrm{C}$

Advanced

Characterization

Scanning Electron Microscopy (SEM) imaging was used to examine the surface morphology of the corrosion products formed on steel surfaces. It reveals the generation of porous structure on the surfaces

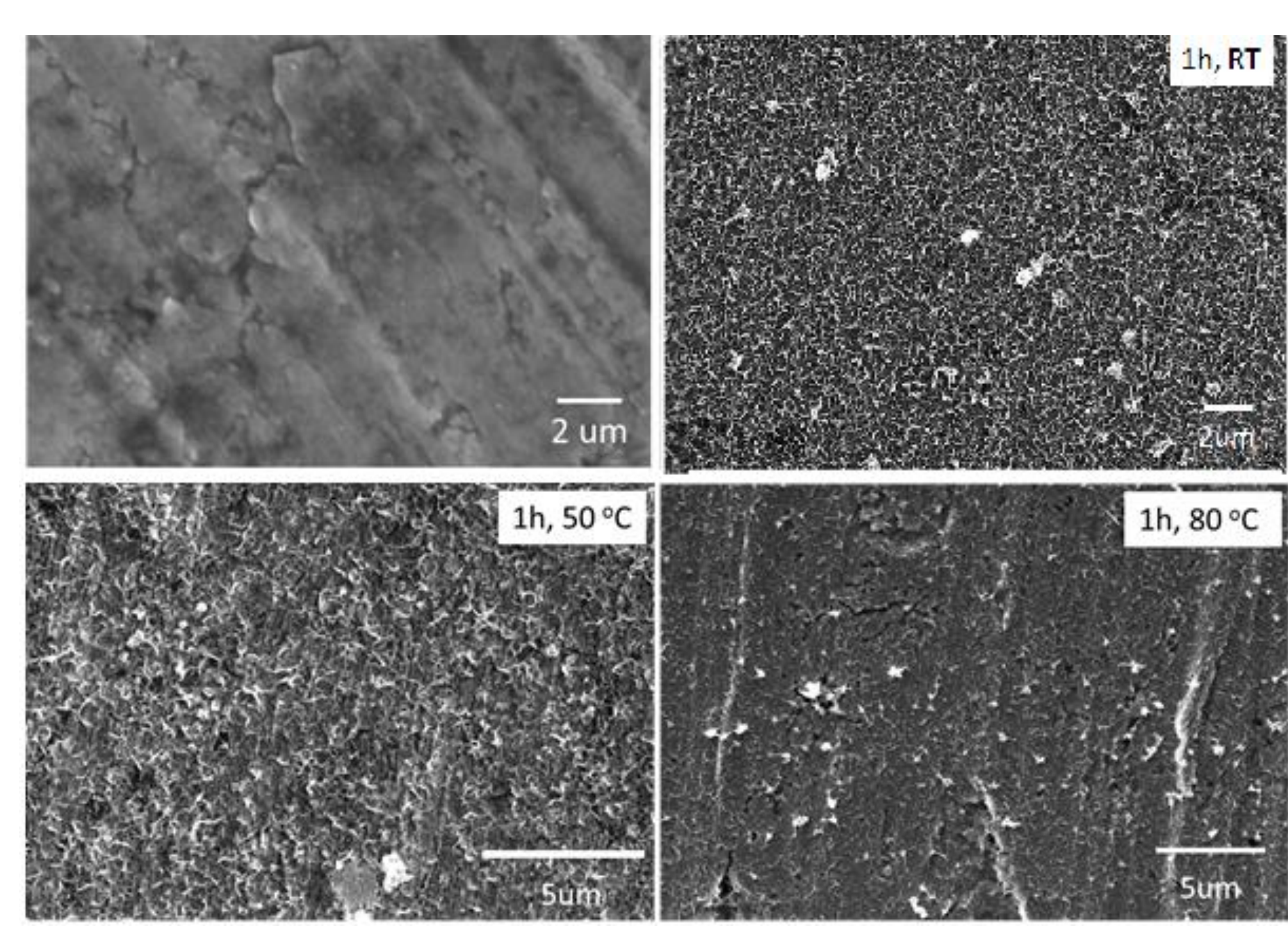

Figure 3: SEM imaging for:(A) unreacted carbon steel, (B) $\mathrm{FeS}$ at $1 \mathrm{hr}-\mathrm{RT}$, (C) $\mathrm{FeS}$ at $1 \mathrm{hr}-50{ }^{\circ} \mathrm{C}$ (D) $\mathrm{FeS}$ at $1 \mathrm{hr}-80^{\circ} \mathrm{C}$.
High resolution cross-sectional Transmission electron microscopy (TEM) reveals complex multi-layer film formed with nanoscale porosity. Both the scale thickness and porosity are found to be temperature dependent.

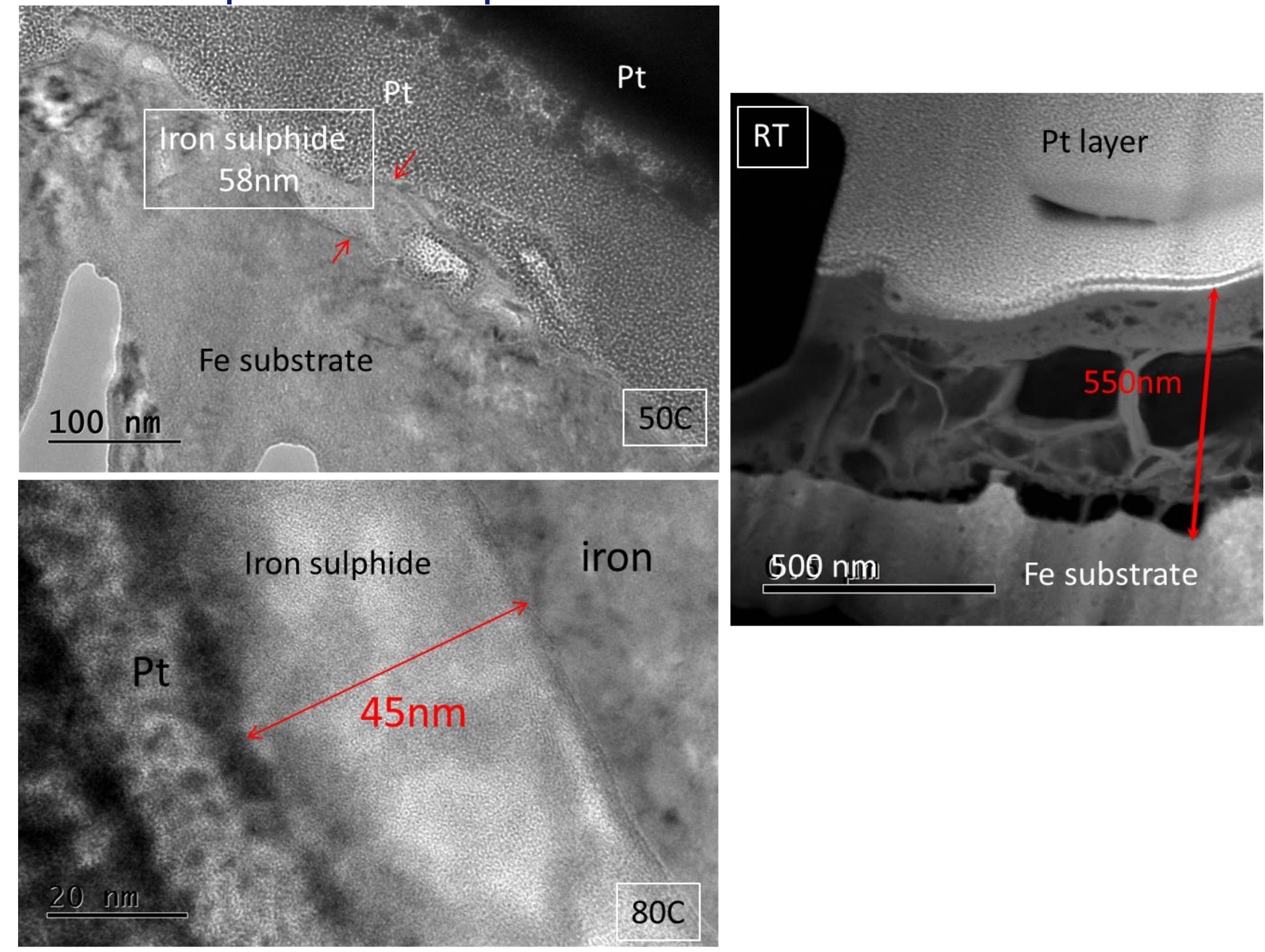

Figure 4: S/TEM images show the comparison of the thickness of the iron sulfide scale ormed at $\mathrm{RT}, 50{ }^{\circ} \mathrm{C}$ and $80^{\circ} \mathrm{C}$, reaction time 1 hour for all (note the Pt layer is added to protect the surface during ion milling of the cross section)

In situ Raman Spectroscopy experiments have been carried out using a newly installed spectrometer from Renishaw (combined with ESEM and complementary optical system). The results from ex situ experiments showed a chemically heterogeneous surface, with different iron sulfide species. In situ data show a transition (possible crystallization) in the structure of the film formed with time.

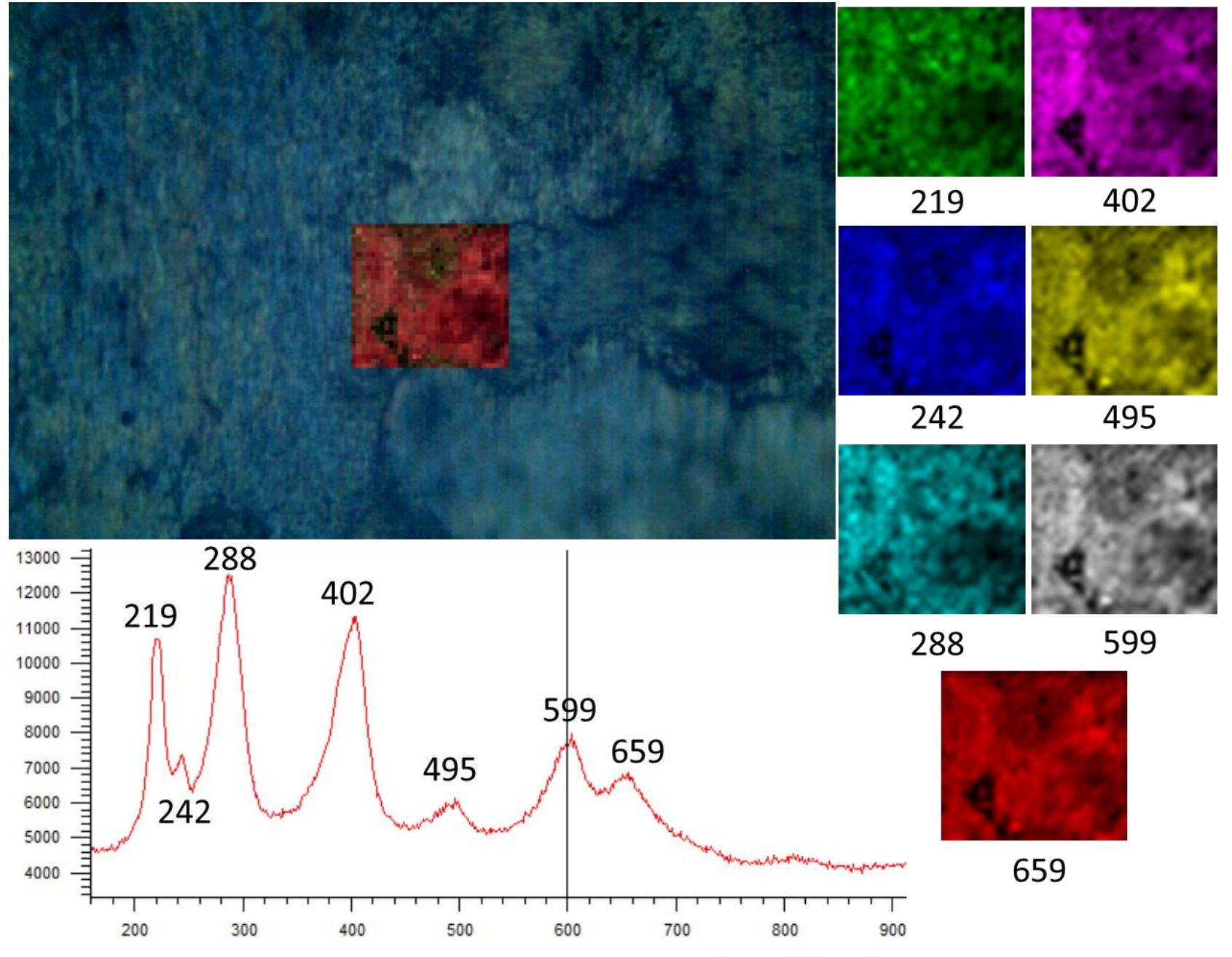

A)

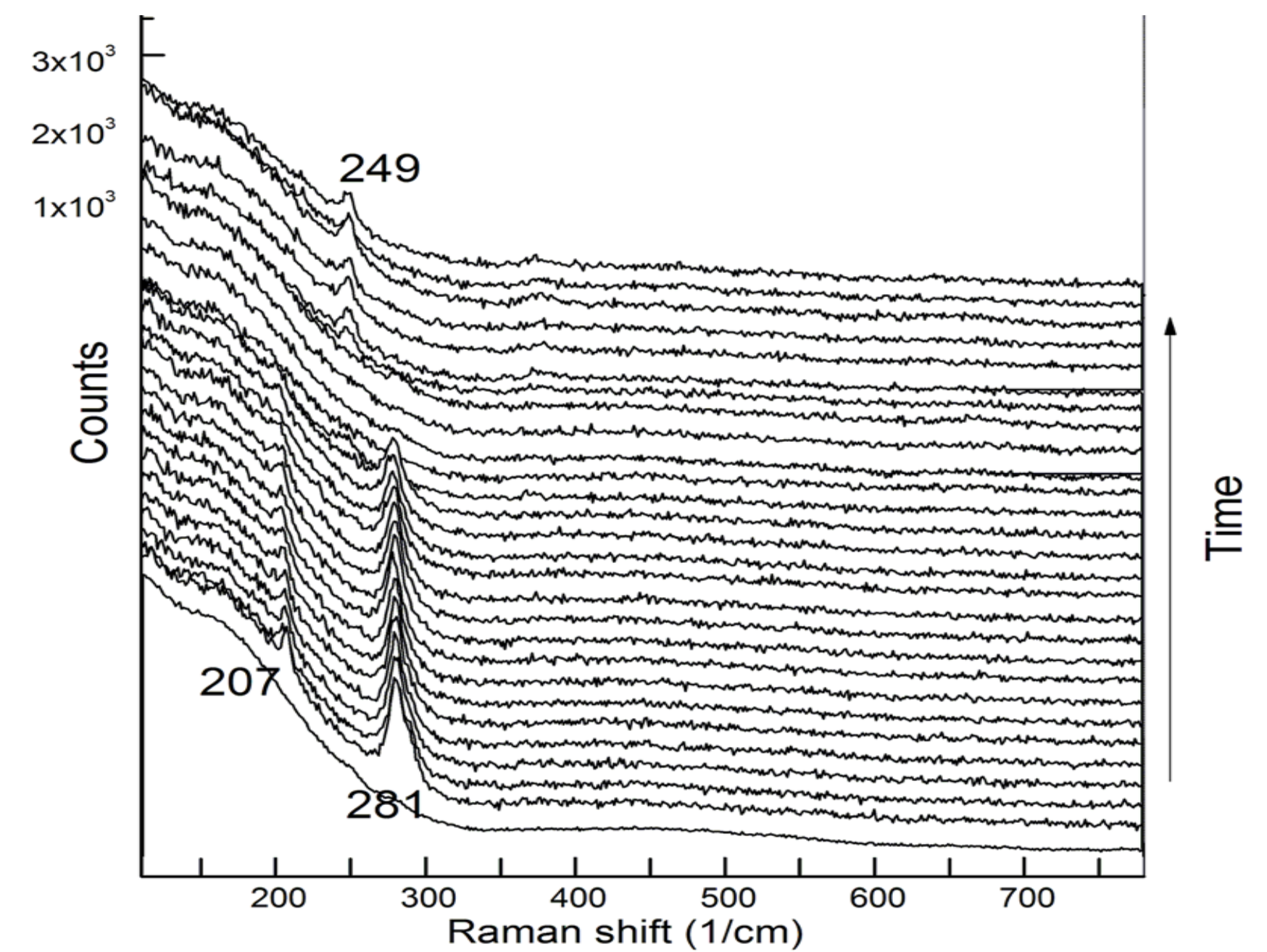

B)
Figure 5: A) Raman maps show distribution of different forms, B) In situ Raman spectra showing early stage iron sulfide formation/evolution

\begin{tabular}{|c|c|c|c|}
\hline Name & Chemical formula & Raman bands positions & reference \\
\hline Nanocrystalline mackinawite & $\mathrm{FeS}$ & $208 ; 282$ & (Bourdoiseau et al. 2008) \\
\hline Well crystalline mackinawite & $\mathrm{FeS}$ & $208 ; 250 ; 298$ & (Bourdoiseau et al. 2008) \\
\hline Greigite & $\mathrm{Fe}_{3} \mathrm{~S}_{4}$ & $138 ; 188 ; 255 ; 350 ; 365$ & (Rémazeilles et al. 2010) \\
\hline Pyrite & $\mathrm{FeS}_{2}$ & $343,349,430$ & (White, 2009) \\
\hline
\end{tabular}

Summary and Future Directions

- The morphology and chemical structure of iron sulphide formed on the Fe substrate have been investigated at different time scales by SEM, TEM and Raman Spectroscopy. A multi-layered nanoporous structure is formed on the surface of steel on exposure to saturated $\mathrm{H}_{2} \mathrm{~S}$. The morphology and thickness of this scale are temperature dependent; linked to variations in the dissolution rate of iron with temperature. The initially formed structure is an amorphous or nanocrystalline structure.

- Further work is underway to determine, in situ, the morphology and structural evolution of iron sulfide with time; and the role of corrosion inhibitors in scale formation and stability.

- Combined electrochemical methods to measure the corrosion rate during $\mathrm{H}_{2} \mathrm{~S}$ exposure, along with methods to evaluate under deposit behaviour are being set up in our laboratories.

\section{Acknowledgements}

This research is funded by Qatar Shell and Shell Global Solutions via the Centre for advanced Interfacial Materials Science (AIMS). In addition, NAQ is grateful for a PhD scholarship from Qatar University.

\section{References}

1. Jin, P., Nesic, S. \& Wolf, H.A., 2015. Analysis of corrosion scales formed on steel at high temperatures in hydrocarbons containing model naphthenic acids and sulfur compounds. Surface and Interface Analysis, (November 2014).

2. Nasr-El-Din, H. \& Al-Humaidan, A., 2001. Iron Sulfide Scale: Formation Removal and Prevention. International Symposium on Oilfield Scale, p.13.

3. Sun, W., 2006. Kinetics of Iron Carbonate and Iron Sulfide Scale Formation In CO2/H2S Corrosion. Ohio University. 